RASĀYAN J. Chem.

Vol. 14 | No. 2 |785-793| April - June | 2021 ISSN: 0974-1496 | e-ISSN: 0976-0083 | CODEN: RJCABP http://www.rasayanjournal.com http://www.rasayanjournal.co.in

\title{
KINETIC ANALYSIS OF OXIDATION OF $\alpha$-HYDROXY ACIDS BY CARO'S ACID IN MICELLAR MEDIUM
}

\author{
P. Rajkumar ${ }^{1, \bowtie}$, N. Buvaneswari ${ }^{2}$, Z. Abdul Vaheith ${ }^{3}$, A. Fiaz Ahamed ${ }^{4}$, \\ G. Saraswathy ${ }^{5}$ and R. Dayanandhan ${ }^{6}$ \\ ${ }^{* 1}$ Department of Chemistry, Priyadarshini Engineering College, Vaniyambadi-635 751, \\ Tirupattur District, Tamil Nadu, India. \\ ${ }^{2}$ Department of Chemistry, Government College of Engineering, Dharmapuri- 636704 , \\ Tamil Nadu, India. \\ ${ }^{3}$ Department of Chemistry, C. Abdul Hakeem College of Engineering \& Technology, \\ Melvisharam-632 014, Vellore District, Tamil Nadu, India. \\ ${ }^{4}$ PG \& Research Department of Chemistry, Islamiah College, Vaniyambadi-635 751, \\ Tamil Nadu, India. \\ ${ }^{5}$ Department of Chemistry, Government College of Engineering, Bargur- 635104, Tamil Nadu, \\ India. \\ ${ }^{6}$ Department of Chemistry, Sri Vidya Mandir Arts and Science College, Uthangarai-636 902, \\ Tamil Nadu. \\ ${ }^{\circledR}$ Corresponding Author: drprajkumar2014@gmail.com
}

\begin{abstract}
The oxidation of Pentaamminecobalt(III) complexes of bounded and boundless $\alpha$-hydroxy acids by Caro's acid is assessed in micelles medium and the rate of the reaction is investigated through a UV-Visible spectrophotometer at $504 \mathrm{~nm}$. The addition of micelles to Pentaamminecobalt(III) complexes of bounded and boundless $\alpha$-hydroxy acids under stable solution conditions boost the rate of the reaction. The rate of the reaction results in first-order kinetics each on [ $\alpha$-hydroxy acids] and [Caro's acid]. The experiment has been performed at five different temperatures and the activation parameters have been evaluated. The consistency of kinetic and stoichiometric data with appropriate mechanisms is established.
\end{abstract}

Keywords: $\alpha$-Hydroxy Acids, Caro’s Acid, Cobalt, Kinetics, Micelles, Oxidation, Stoichiometry.

RASĀYAN J. Chem., Vol. 14, No.2, 2021

\section{INTRODUCTION}

On persuing literature, it is ascertained that there is no evidence for the kinetics of oxidation of $\alpha$-hydroxy acids by Caro's acid. The aim of this is to determine induced electron transfer reactions in Pentaamminecobalt(III) complexes of both bounded and boundless $\alpha$-hydroxy acids with Caro's acid in presence of micelles. ${ }^{1-4}$ Primary aliphatic alcohols may be oxidized either as alcohols, yielding equivalent oxoacids or they may undergo oxidative decarboxylation to yield a ketone. The structure of pyridinium fluorochromate $^{5}$, quinolinium fluorochromate ${ }^{6}$, isoquinolinium dichromate ${ }^{7}$, tetrahydropyranyl ethers ${ }^{8}$, and tetraethylammonium chlorochromate ${ }^{9}$, have been used to analyze the kinetics and mechanism of diverse organic compounds. As Caro's acid is a liquid at room temperature, the S(VI) core adopts its characteristics tetrahedral geometry. It is one of the strongest oxidants and is highly flammable. The micelles Sodium laurylsulphate (NaLS), Cetyltrimethylammonium bromide (CTAB) and TRITON-X 100 are utilized in the present study. The bounded ligands like $\alpha$-hydroxy acids, dicarboxylic acids, $\alpha$-amino acids, have a saturated fragment segregating cobalt(III) from the area of initial reaction irradiation. Cobalt(III) complexes may act as a reduction at the cobalt(III) center and carbon-carbon fission ${ }^{10}$. To accomplish such a process, kinetic studies on the rates of disappearance of cobalt(III) coupled with rates of formation of cobalt(II) and organic products will be beneficial. This is the basis for the present work, along with the inference of quantum yield in each case. The correlation between quantum yield and the electronic influence can also be studied. By the inner-sphere mechanism, the reaction has been obtained. 
RASĀYAN J. Chem.

Vol. 14 | No. 2 |785-793| April - June | 2021

\section{EXPERIMENTAL}

\section{Materials and Methods}

Caro's acid has been employed as an oxidant both in acid and alkaline media for the oxidation of a huge number of compounds. The $\alpha$-hydroxy acids such as mandelic acid, lactic acid $\&$ glycolic acid are prepared as their perchlorates by the literature method. ${ }^{11}$ Their perchlorate complex structure is consistent with FT-IR spectra.

Solvents like ethanol, methanol, ether and perchloric acid were purified by ordinary methods. Product analysis carried out to determine the yield of cobalt(II) is nearly $100 \%$. The micelles are purified by the procedure existing in the literature. ${ }^{12}$ The commercial samples of the micelles are being washed repetitively with anhydrous ether and have been recrystallized many times from alcohol with the addition of anhydrous ether. The chemicals used are E. Merck and BDH annular and the conductivity water is used to prepare all solutions.

The kinetics studies are carried out by allowing reactions in glass stopper corning glass vessels. ${ }^{13}$ The reaction mixture $(5 \mathrm{~mL})$ of the solution is titrated against sodium thiosulphate using starch as an indicator. The rate of the reaction (-dc/dt) in each kinetic run is resolute by the slope of the tangent drawn at a fixed concentration of Caro's acid. The rate scopes are performed at $60 \pm 0.2^{\circ} \mathrm{C}$ in $100 \%$ aqueous medium for $\alpha$ hydroxy acids. The temperature is restricted by an electrically operated thermostat. According to literature ${ }^{14}$, the presence of free radicals in the reaction is estimated. Ionic strength is maintained by the addition of small measures of $\mathrm{H}_{2} \mathrm{SO}_{4}$. The concentration of micelles and $\alpha$-hydroxy acids vary in the range $[0.1-0.5] \times 10^{2} \mathrm{~mol} \mathrm{dm}^{-3}$. The temperatures also vary from $50-70 \pm 0.2^{\circ} \mathrm{C} .{ }^{15}$ The reaction is firstorder concerning the $\alpha$-hydroxy acids. ${ }^{16,17}$ The second-order plots are also made for comparing $\alpha$-hydroxy acids and micelles. The values reported are the averages of the last two runs.

\section{RESULTS AND DISCUSSION}

The rate and other experimental data for all the studies of $\alpha$-hydroxy acids have been obtained. Since the results are analogous, only representative data have been obtained here.

\section{Stoichiometric Studies}

The stoichiometric scrutiny for Caro's acid oxidation of Pentaamminecobalt(III) complexes of $\alpha$-hydroxy acids and boundless ligand in the presence of micelles are analyzed at $60 \pm 0.2^{\circ} \mathrm{C}$ Table- 1 .

The concentration of Caro's acid was obtained both iodometrically and spectrophotometrically from the change in absorbance observed at $504 \mathrm{~nm}$. $\Delta$ [Caro's acid] is evaluated after applying the due blank corrections for decomposition of Caro's acid and aquation of Co(III) complex of $\alpha$-hydroxy acids in the presence of micelles. Similar computation about $\Delta[$ Caro's acid] is made for the boundless ligand also. The ratio between reacted [oxidant] and [substrate] yields stoichiometry. This value was then compared with the amount of cobalt(III), carbonyl compound and cobalt(III) keto acid complex. ${ }^{18-21}$

The stoichiometry results explain that for 1.0 mole of cobalt (III) complex, about 0.5 moles of Caro's acid is consumed, though with the boundless ligands for 1.0 mole of $\alpha$-hydroxy acids consumed 1.0 mole of Caro's acid are consumed. Product and Stoichiometric investigation if approved for the oxidation of complexes and free ligands in three different (Anionic, Cationic \& Neutral) micelles medium with increasing micelles concentration an enhance in the rate is observed.

\section{Effect of Ionic Strength}

The kinetic analysis is carried out at various ionic strengths, $0.1,0.2,0.3$ and 0.4 , using a relevant mixture of $\alpha$-hydroxy acids and sulphuric acid. Ionic strength increases the rate of reaction. The rate constants are summarized in Table-2 and illustrated in (Fig.-1). It displays an increase in the concentration of ionic strength of solvent increases in the rate constant.

\section{Effect of Temperature}

The rate of reaction is very susceptible to temperature. The rate of reaction increases with temperature. The slow reaction rate at ordinary temperatures may become considerable or even explosive at high temperatures. The kinetics of oxidation of $\alpha$-hydroxy acids by Caro's acid is performed at four various 
RASĀYAN J. Chem.

Vol. 14 | No. 2 |785-793| April - June | 2021

temperatures $(303 \mathrm{~K}, 308 \mathrm{~K}, 313 \mathrm{~K} \& 318 \mathrm{~K})$ maintaining other experimental conditions constant. The second-order rate constants calculated are shown in Table-3. It is observed that the enthalpy of activation, entropy of activation and free energy of activation are completed from $\mathrm{k}_{2}$ at $303,308,313$ \& $318 \mathrm{~K}$ using the Arrhenius and Eyring plots. ${ }^{22,23}$

The thermodynamic parameters for the oxidation of lactic acid are $\Delta \mathrm{H}^{\#}=55.59 \pm 1.5 \mathrm{~kJ} / \mathrm{mol},-\Delta \mathrm{S}^{\#}=130.58$ $\pm 4.5 \mathrm{~J} / \mathrm{K} / \mathrm{mol}$, and $\Delta \mathrm{G}^{\#}=91.97 \pm 2.5 \mathrm{~kJ} / \mathrm{mol}$. It is observed that the Arrhenius plot of $\log \mathrm{k}_{2}$ versus $1 / \mathrm{T}$ is linear.

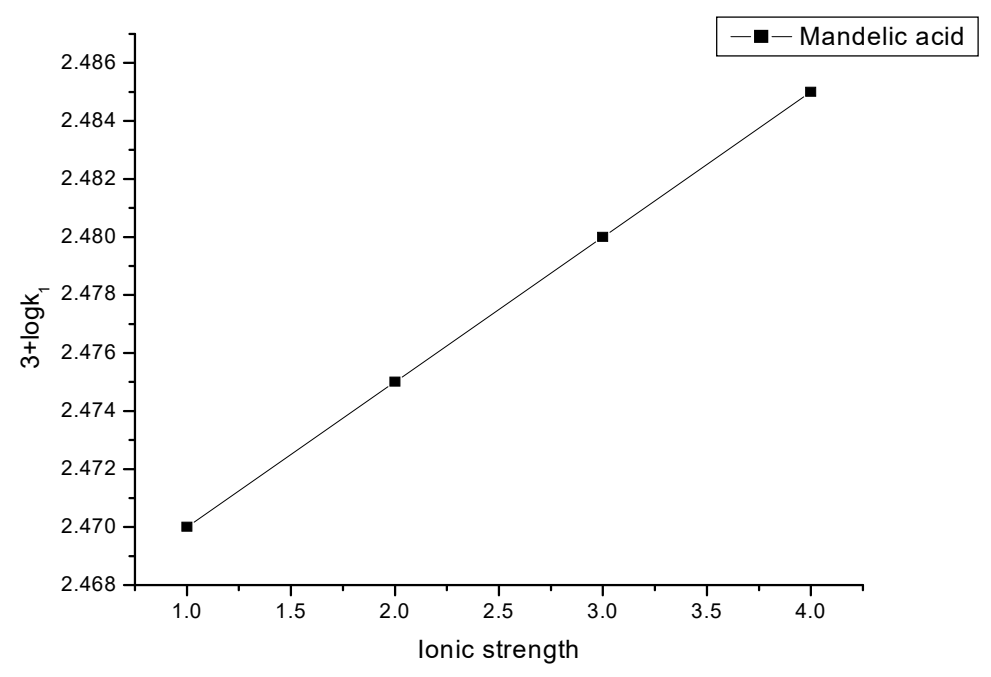

Fig.-1: Plot of $3+\operatorname{logk} 1$ Versus Ionic Strength of $\alpha$-hydroxy Acids in Sulphuric Acid

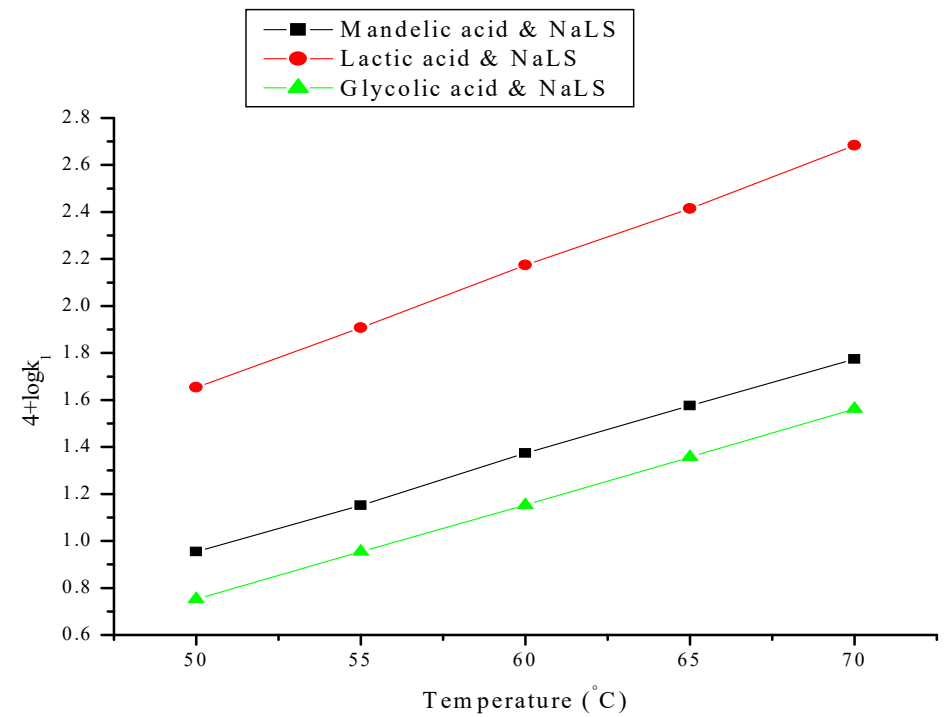

Fig.-2: Dependence of Rate on [ $\alpha$-hydroxy acids] in the presence of NaLS with Various Temperatures

\section{Polymerization of Acrylonitrile}

The oxidations of $\alpha$-hydroxy acids by Caro's acid in an environment of nitrogen fail to induce the polymerization of acrylonitrile. Adding acrylonitrile does not affect the rate. The reaction mechanism confirms the absorbance of free radical. ${ }^{24}$ 
RASĀYAN J. Chem.

Vol. 14 | No. 2 |785-793| April - June | 2021

Table-1: Stoichiometric Data for Caro's Acid Oxidation of Cobalt(III) bounded and unbounded $\alpha$-hydroxy acids in the presence of Micelles Caro's Acid $=0.08 \mathrm{~mol} \mathrm{dm}^{-3},\left[\mathrm{H}_{2} \mathrm{SO}_{4}\right]=0.25 \mathrm{~mol} \mathrm{dm}^{-3}$, [Micelles] $=1.00 \times 10^{-3} \mathrm{~mol} \mathrm{dm}^{-3}$, $\left[\left(\mathrm{NH}_{3}\right)_{5} \mathrm{Co}(\mathrm{III})-\mathrm{L}\right]^{2}=[0.1-0.4] \times 10^{2} \mathrm{~mol} \mathrm{dm}^{-3}$, Temperature $=60 \pm 0.2^{\circ} \mathrm{C}$.

\begin{tabular}{|c|c|c|c|c|}
\hline $\begin{array}{c}10^{3}[\text { Compound }] \\
\mathrm{mol} \mathrm{dm}\end{array}$ & $\begin{array}{c}10^{2}[\text { CARO'S } \\
\text { ACID }]_{\text {initial }} \\
\text { mol dm }^{-3}\end{array}$ & $\begin{array}{c}10^{2}[\text { CARO'S } \\
\text { ACID }]_{\text {final }} \\
\text { mol dm }^{-3}\end{array}$ & $\begin{array}{c}\Delta 10^{3}[\text { [CARO'S } \\
\text { ACID] } \\
\text { mol dm}^{-3}\end{array}$ & $\begin{array}{c}\text { [Compound: } \\
\Delta \text { [CARO'S } \\
\text { ACID] }\end{array}$ \\
\hline \multicolumn{5}{|l|}{ Mandelic acid } \\
\hline 1.0 & 1.0 & 0.89 & 1.10 & $1.00: 1.10$ \\
\hline 2.0 & 2.0 & 1.81 & 2.01 & $1.00: 1.01$ \\
\hline 4.0 & 2.0 & 1.62 & 4.02 & $1.00: 1.03$ \\
\hline \multicolumn{5}{|l|}{ Lactic acid } \\
\hline 1.0 & 1.0 & 0.91 & 1.02 & $1.00: 1.00$ \\
\hline 2.0 & 2.0 & 1.82 & 1.91 & $1.00: 0.99$ \\
\hline 4.0 & 2.0 & 1.61 & 4.01 & $1.00: 1.01$ \\
\hline \multicolumn{5}{|l|}{ Glycolic acid } \\
\hline 1.0 & 1.0 & 0.89 & 1.20 & $1.00: 1.21$ \\
\hline 2.0 & 2.0 & 1.79 & 2.21 & $1.00: 1.11$ \\
\hline 4.0 & 2.0 & 1.58 & 4.31 & $1.00: 1.08$ \\
\hline \multicolumn{5}{|l|}{ Mandelato } \\
\hline 1.0 & 1.0 & 0.98 & 0.52 & $2.00: 1.01$ \\
\hline 2.0 & 2.0 & 1.90 & 1.11 & $2.00: 1.12$ \\
\hline \multirow{2}{*}{\multicolumn{5}{|c|}{ Lactato }} \\
\hline & & & & \\
\hline 1.0 & 1.0 & 0.97 & 0.50 & $2.00: 0.99$ \\
\hline 2.0 & 2.0 & 1.91 & 1.01 & $2.00: 1.01$ \\
\hline 4.0 & 2.0 & 2.01 & 2.01 & $2.00: 1.02$ \\
\hline \multicolumn{5}{|l|}{ Glycolato } \\
\hline 1.0 & 1.0 & 0.96 & 0.51 & $2.00: 1.02$ \\
\hline 2.0 & 2.0 & 1.89 & 1.21 & $2.00: 1.23$ \\
\hline 4.0 & 2.0 & 1.99 & 2.01 & $2.00: 1.00$ \\
\hline
\end{tabular}

Table-2: Kinetic Rate Data for Oxidation of $\alpha$-hydroxy acids in Sulphuric Acid at a Constant Ionic Strength Caro's Acid $=0.08 \mathrm{~mol} \mathrm{dm}^{-3},\left[\mathrm{H}_{2} \mathrm{SO}_{4}\right]=0.25 \mathrm{~mol} \mathrm{dm}^{-3},[\alpha$-hydroxy acids $]=[0.1-0.4] \times 10^{2} \mathrm{~mol} \mathrm{dm}^{-3}$, Temperature $=60 \pm 0.2^{\circ} \mathrm{C}$.

\begin{tabular}{c|c|c}
\hline $10^{3}$ Substrate & {$\left[\mathrm{H}_{2} \mathrm{SO}_{4}\right]$} & $10^{3} \mathrm{k}_{1} \mathrm{~s}^{-1}$ \\
\hline Mandelic acid & 0.1 & 2.470 \\
& 0.2 & 2.475 \\
& 0.3 & 2.480 \\
Lactic acid & 0.4 & 2.485 \\
& 0.1 & 3.750 \\
Glycolic acid & 0.2 & 3.755 \\
& 0.3 & 3.760 \\
& 0.4 & 3.765 \\
& 0.1 & 3.100 \\
& 0.2 & 3.105 \\
& 0.3 & 3.110 \\
\hline
\end{tabular}

Dependence of Rate on Caro's Acid Oxidation of $\alpha$-hydroxy Acids in the Presence of Micelles with Various Temperatures

The effect of varying the temperature with micelles on the rate of Caro's acid oxidation of $\alpha$-hydroxy acids has been carried out in the range of $50,55,60,65,70 \pm 0.2^{\circ} \mathrm{C}$ for $\mathrm{NaLS}, \mathrm{CTAB} \& \mathrm{TRITON}-\mathrm{X} 100$ Table-4. 
RASĀYAN J. Chem.

Vol. 14 | No. 2 |785-793| April - June | 2021

Table-3: Activation parameters and second-order rate constants for the oxidation of $\alpha$-hydroxy acids by Caro's acid Caro's acid $=0.08 \mathrm{~mol} \mathrm{dm}^{-3},\left[\mathrm{H}_{2} \mathrm{SO}_{4}\right]=0.25 \mathrm{~mol} \mathrm{dm}^{-3},[\alpha$-hydroxy acids $]=[0.1-0.4] \times 10^{2} \mathrm{~mol} \mathrm{dm}^{-3}$

\begin{tabular}{|c|c|c|c|c|c|c|c|}
\hline Substrate & \multicolumn{4}{|c|}{$10^{2} \mathrm{X} \mathrm{k}_{2} \mathrm{dm}^{3} / \mathrm{mol} / \mathrm{sec}$} & $\Delta \mathrm{H}^{\#} \quad(\mathrm{~kJ} / \mathrm{mol})$ & $-\Delta \mathrm{S}^{\#}(\mathrm{~J} / \mathrm{K} / \mathrm{mol})$ & $\Delta \mathrm{G}^{\#}(\mathrm{~kJ} / \mathrm{mol})$ \\
\hline Lactic Acid & $\begin{array}{c}303 \mathrm{~K} \\
6.61\end{array}$ & $\begin{array}{c}308 \mathrm{~K} \\
9.12\end{array}$ & $\begin{array}{c}313 \mathrm{~K} \\
0.96\end{array}$ & $\begin{array}{c}318 \mathrm{~K} \\
15.00\end{array}$ & $55.59 \pm 1.5$ & $130.58 \pm 4.5$ & $91.97 \pm 2.5$ \\
\hline
\end{tabular}

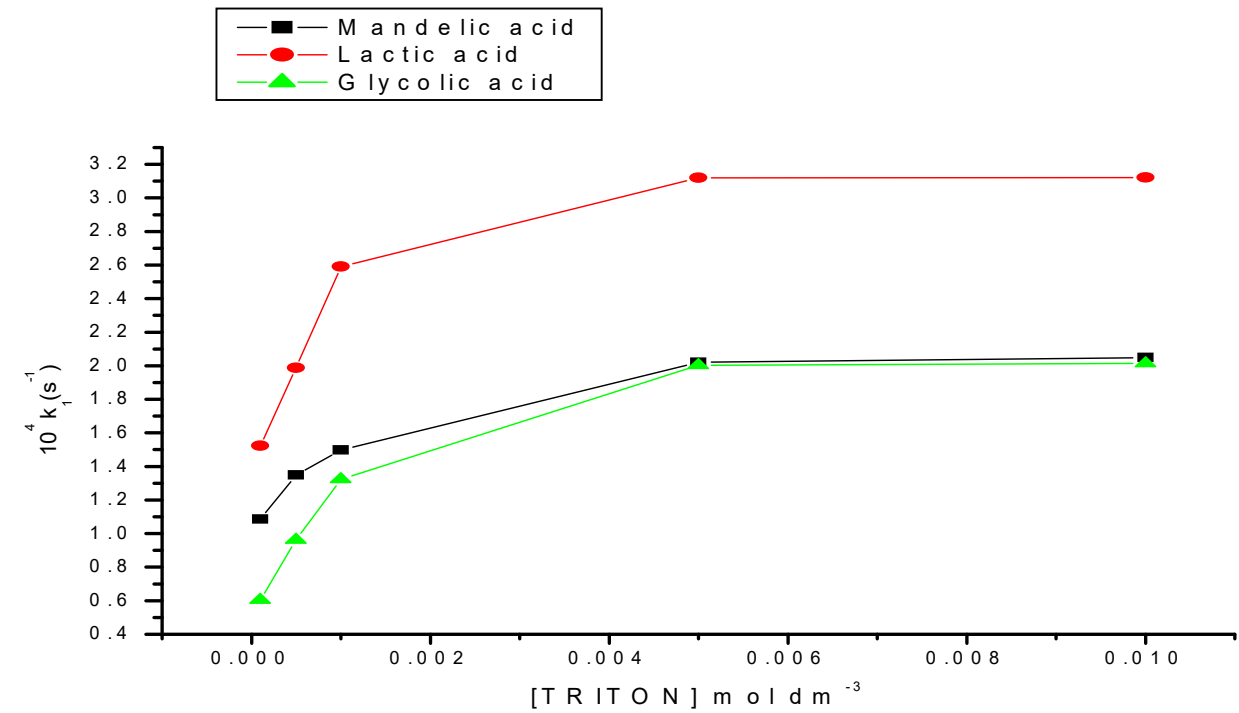

Fig.-3: Dependence of Rate on [TRITON-X 100] Concentration

As the temperature rises, the rate is increased. A graph of $\log \mathrm{k}_{1}$ versus temperature is linear (Figure-2). At a higher temperature of the micelle, the maximum rate occurs. The rate of oxidation of reaction increases much by the addition of CTAB than the addition of NaLS and TRITON-X 100 on similar conditions. The linear pattern of the curve of these micellar catalyzed oxidation reactions resembles that of the enzymatically catalyzed reaction. As they accelerate the rate of oxidation, they are a positive catalyst for these reactions. Had the reaction species been ionic, the reaction would have been accelerated in one micelle and retarded in the other depending on the charge carried by it.

Table-4: Dependence of Rate on Caro's Acid Oxidation of $\alpha$-hydroxy Acids in the Presence of Micelles with Various Temperatures Caro's acid $=0.08 \mathrm{~mol} \mathrm{dm}^{-3},\left[\mathrm{H}_{2} \mathrm{SO}_{4}\right]=0.25 \mathrm{~mol} \mathrm{dm}^{-3},[\alpha$-hydroxy acids $]=$ $0.5 \mathrm{~mol} \mathrm{dm}^{-3}$, [Micelles] $=1.00 \times 10^{-3} \mathrm{~mol} \mathrm{dm}^{-3}$

\begin{tabular}{c|c|c|c|c|c|c|c|c|c}
\hline \multirow{2}{*}{$\begin{array}{c}\text { Temp. } \\
\left({ }^{\circ} \mathrm{C}\right)\end{array}$} & \multicolumn{3}{|c|}{$\begin{array}{c}10^{4} \mathrm{k}_{1}\left(\mathrm{~s}^{-1}\right) \\
\text { Mandelic acid }\end{array}$} & \multicolumn{3}{c|}{$\begin{array}{c}10^{4} \mathrm{k}_{1}\left(\mathrm{~s}^{-1}\right) \\
\text { Lactic acid }\end{array}$} & \multicolumn{3}{|c|}{$10^{4} \mathrm{k}_{1}\left(\mathrm{~s}^{-1}\right)$} \\
& NaLS & CTAB & TRITON & NaLS & CTAB & TRITON & NaLS & CTAB & TRITON \\
\hline 50 & 0.955 & 1.434 & 1.103 & 1.654 & 2.244 & 1.806 & 0.753 & 0.924 & 0.854 \\
55 & 1.151 & 1.628 & 1.304 & 1.907 & 2.442 & 2.002 & 0.954 & 1.115 & 1.05 \\
60 & 1.374 & 1.828 & 1.523 & 2.174 & 2.656 & 2.201 & 1.153 & 1.318 & 1.245 \\
65 & 1.576 & 2.033 & 1.728 & 2.414 & 2.872 & 2.402 & 1.357 & 1.532 & 1.442 \\
70 & 1.774 & 2.235 & 1.962 & 2.684 & 3.092 & 2.612 & 1.562 & 1.752 & 1.672 \\
\hline
\end{tabular}

Dependence of Rate on Caro's Acid Oxidation of $\alpha$-hydroxy Acids in the Presence of NaLS, CTAB and TRITON-X 100

The effect of changing the anionic micelles concentration on the rate of Caro's acid oxidation of $\alpha$ hydroxy acids has been analyzed in the range of $\left[0.5\right.$ to 2.5] $\mathrm{X} 10^{2} \mathrm{~mol} \mathrm{dm}^{-3}$ for NaLS, CTAB \& TRITON-X 100 Table-5. 
RASĀYAN J. Chem.

Vol. 14 | No. 2 |785-793| April - June | 2021

With the increase in the micelle concentration, an enhance in the rate is observed. A graph of $\operatorname{logk}_{1}$ versus micelle concentration is sigmoidal (Fig.-3). At a higher concentration of micelle, a nearly maximum rate has been observed. Added CTAB enhances the rate of oxidation of reaction, much more than added NaLS \& TRITON-X 100 of the same concentration. The sigmoidal pattern of the curve of these micellar catalyzed oxidation reactions resembles that of the enzymatically catalyzed reaction. As they accelerate the rate of oxidation, they act as a positive catalyst for these reactions ${ }^{25}$.

Table-5: Dependence of Rate on Caro's Acid Oxidation of $\alpha$-hydroxy Acids in the Presence of NaLS,

CTAB and TRITON-X 100, Caro's Acid $=0.08 \mathrm{~mol} \mathrm{dm}^{-3},\left[\mathrm{H}_{2} \mathrm{SO}_{4}\right]=0.25 \mathrm{~mol} \mathrm{dm}^{-3}$, [ $\alpha$-hydroxy acids $]=0.5 \mathrm{~mol}$ $\mathrm{dm}^{-3}$, Temperature $=60 \pm 0.2^{\circ} \mathrm{C}$

\begin{tabular}{c|c|c|c|c|c|c|c|c|c}
\hline \multirow{2}{*}{$\begin{array}{c}\text { Conc. } \\
\text { mol dm }\end{array}$} & \multicolumn{3}{|c|}{$[\mathrm{NaLS}] \mathrm{mol} \mathrm{dm}^{-3}$} & \multicolumn{3}{c|}{$[\mathrm{CTAB}] \mathrm{mol} \mathrm{dm}^{-3}$} & \multicolumn{3}{c}{ [TRITON] $\mathrm{mol} \mathrm{dm}^{-3}$} \\
\cline { 2 - 10 } & \multicolumn{3}{|c|}{$10^{4} \mathrm{k}_{1}\left(\mathrm{~s}^{-1}\right)$} & \multicolumn{3}{c|}{$10^{4} \mathrm{k}_{1}\left(\mathrm{~s}^{-1}\right)$} & \multicolumn{3}{c}{$10^{4} \mathrm{k}_{1}\left(\mathrm{~s}^{-1}\right)$} \\
\cline { 2 - 10 } & M.A & L.A & G.A & M.A & L.A & G.A & M.A & L.A & G.A \\
\hline 0.0001 & 0.124 & 1.756 & 1.075 & 1.198 & 2.209 & 0.329 & 1.086 & 1.523 & 0.605 \\
0.0005 & 1.222 & 1.926 & 1.126 & 1.789 & 2.748 & 0.689 & 1.349 & 1.987 & 0.962 \\
0.001 & 1.444 & 2.106 & 1.233 & 1.929 & 2.999 & 0.898 & 1.498 & 2.591 & 1.324 \\
0.005 & 1.602 & 2.216 & 1.283 & 2.189 & 3.298 & 0.991 & 2.020 & 3.120 & 2.003 \\
0.01 & 1.621 & 2.226 & 1.296 & 2.199 & 3.299 & 1.009 & 2.048 & 3.121 & 2.014 \\
\hline
\end{tabular}

\section{Mechanism}

Caro's acid oxidizes the $\mathrm{OH}$ Centre of both bounded and unbounded $\alpha$-hydroxy acids at a rate comparable to that of the free ligand results in $100 \%$ reduction at the Proton Centre. It forms Caro's acid ester which can decompose in a slow step and pass through $\mathrm{C}-\mathrm{C}$ bond fission leading to the formation of carbonyl compounds with the emission of carbon dioxide and $\mathrm{H}_{2}$ gas.

Given the above statements, the reaction Schemes- 1 and 2 have been projected for Caro's acid oxidation of Pentaamminecobalt(III) complexes of $\alpha$-hydroxy acids.

\section{Spectral Details}

The IR Spectral data (Fig.-4) for Pentaamminecobalt(III) mandelato complex reveals the presence of these compounds $3772,3782,3819,3861,3876 \mathrm{~cm}^{-1}$ stretching bond frequency for five $-\mathrm{NH}_{3}$ groups, $3259 \mathrm{~cm}^{-1}$ stretching bonds for $-\mathrm{OH}$ group. $2933 \mathrm{~cm}^{-1}$ stretching bond frequency for -aromatic -C-H group, $1620 \mathrm{~cm}^{-1}$ stretching bond frequency for $-\mathrm{C}=\mathrm{O}$ group, $2688 \mathrm{~cm}^{-1}$ for $-\mathrm{C}-\mathrm{H}$ bond and $1381 \mathrm{~cm}^{-1}$ for $-\mathrm{C}-\mathrm{O}$ stretching bond frequency. The IR spectral data (Figure-5) for Pentaamminecobalt(III) lactato complex reveals the presence of these compounds, 3724, 3778, 3828, 3882 and $3930 \mathrm{~cm}^{-1}$ for five $\mathrm{NH}_{3}$ groups, $3277 \mathrm{~cm}^{-1}$ broad peaks for $-\mathrm{OH}$ group, $2763 \mathrm{~cm}^{-1}$ for $-\mathrm{CH}_{3}$ group, $1616 \mathrm{~cm}^{-1}$ for $\mathrm{C}=\mathrm{O}$ group and $1382 \mathrm{~cm}^{-1}$ for $-\mathrm{C}-\mathrm{O}$ group.

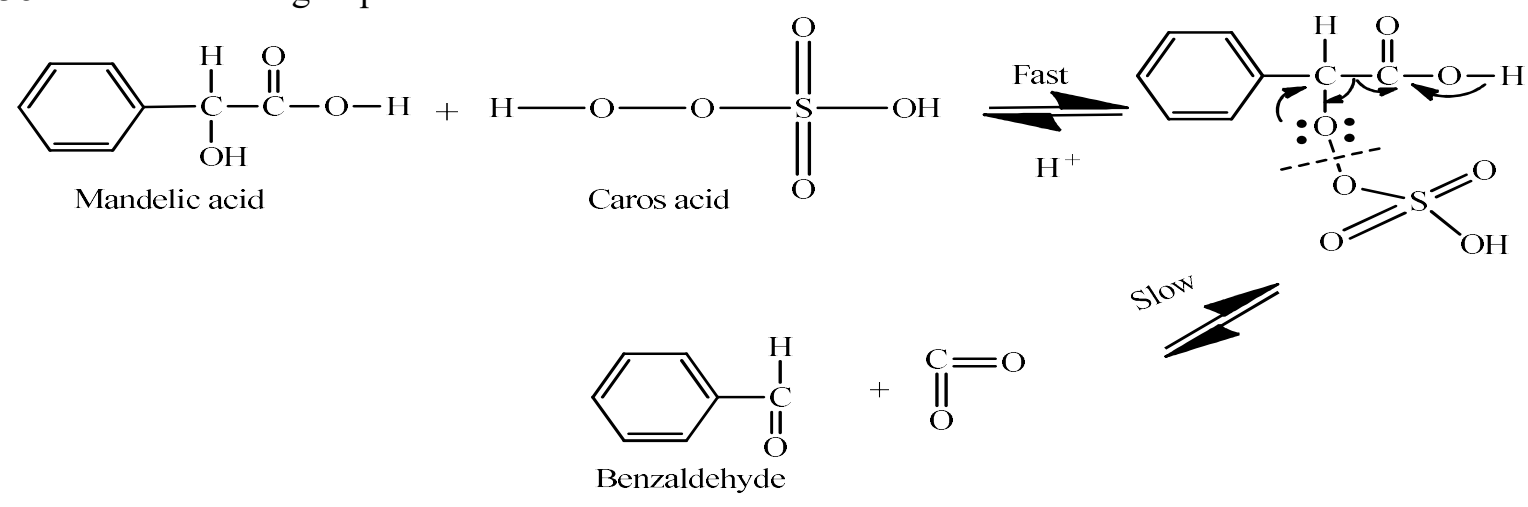

Scheme-1 
RASĀYAN J. Chem.

Vol. 14 | No. 2 |785-793| April - June | 2021

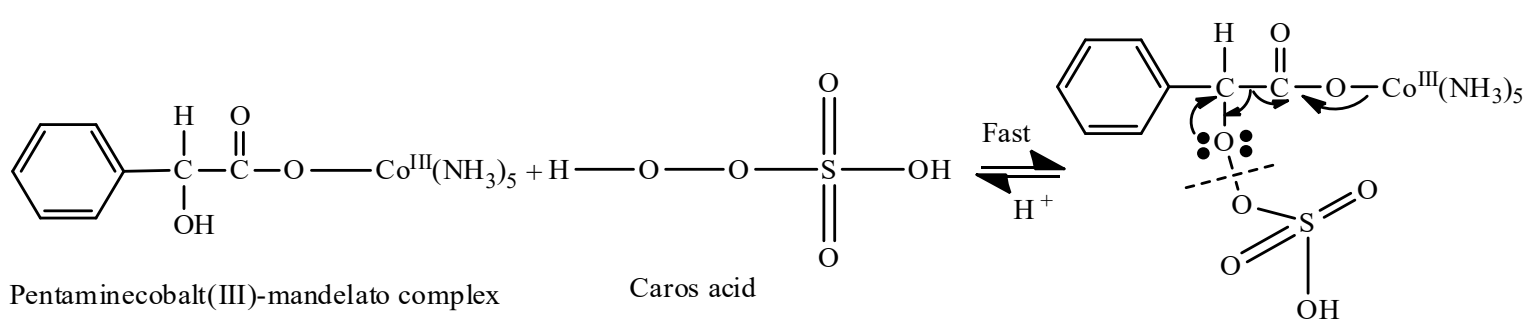

Transistion state assumed

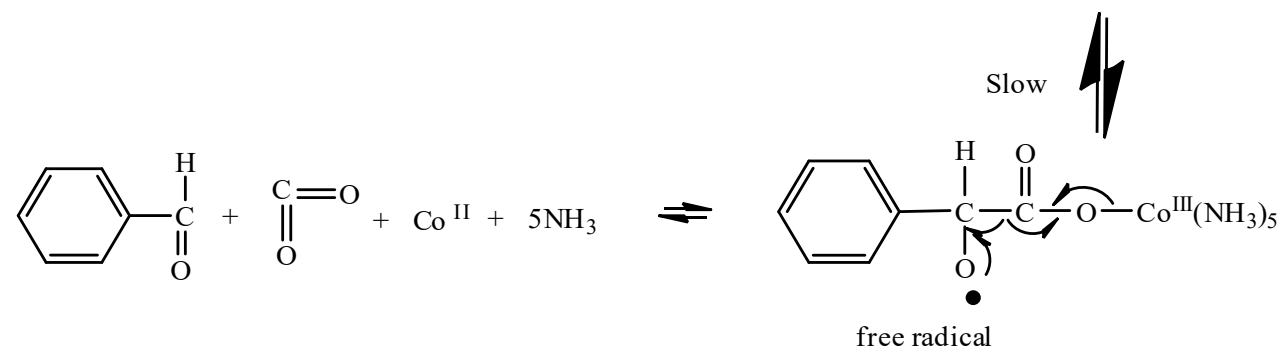

Scheme-2

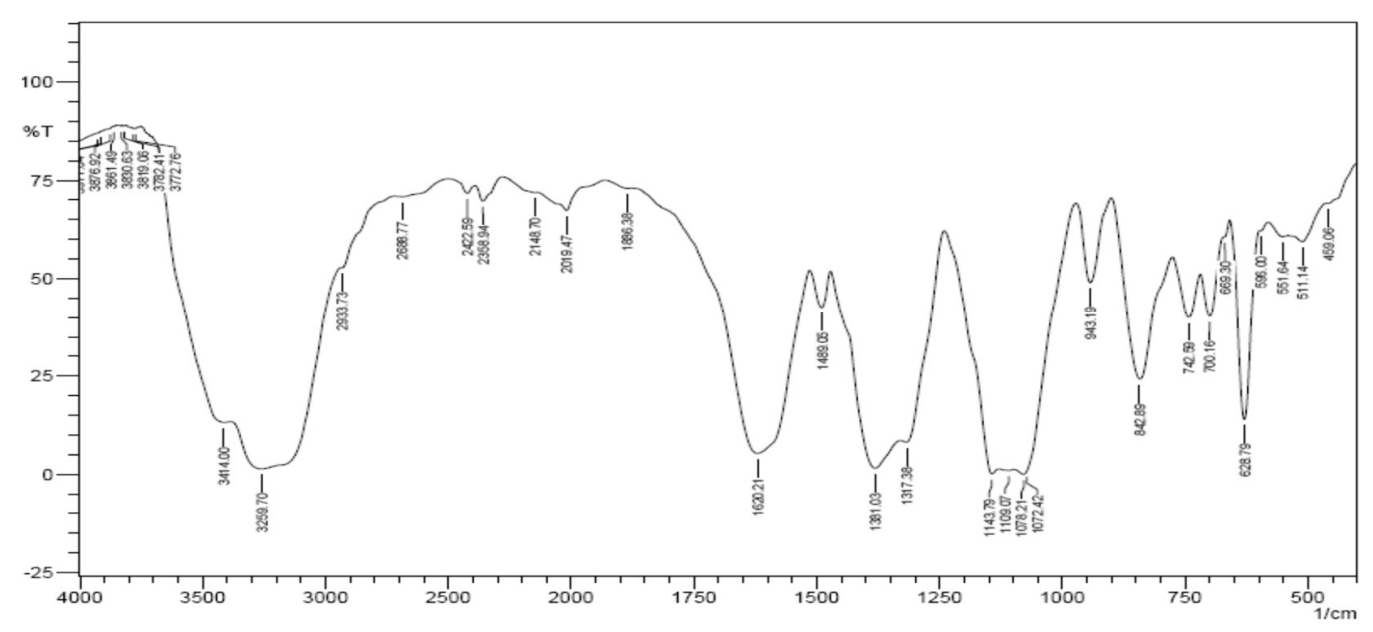

Fig.-4: FT-IR Spectrum of Pentaamminecobalt(III)-Mandela to Complex

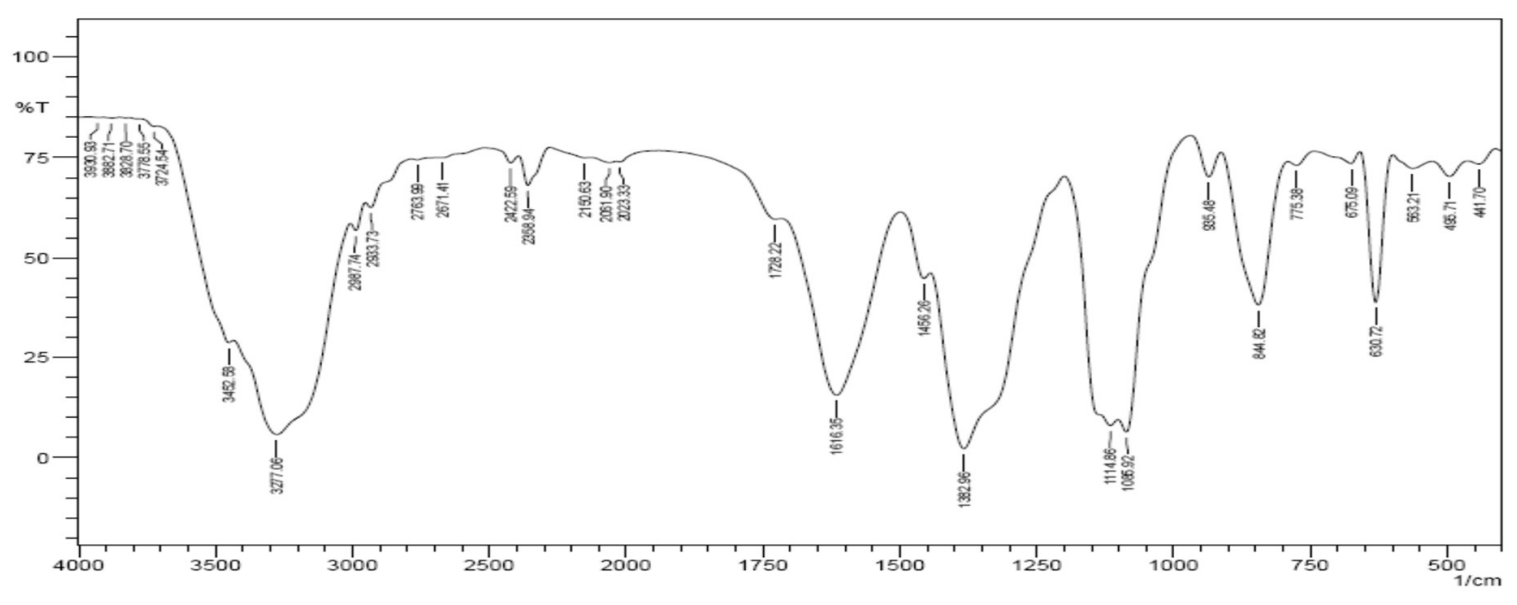

Fig.-5: FT-IR Spectrum of Penetaamminecobalt(III)-Lactato Complex 
RASĀYAN J. Chem.

Vol. 14 | No. 2 |785-793| April - June | 2021

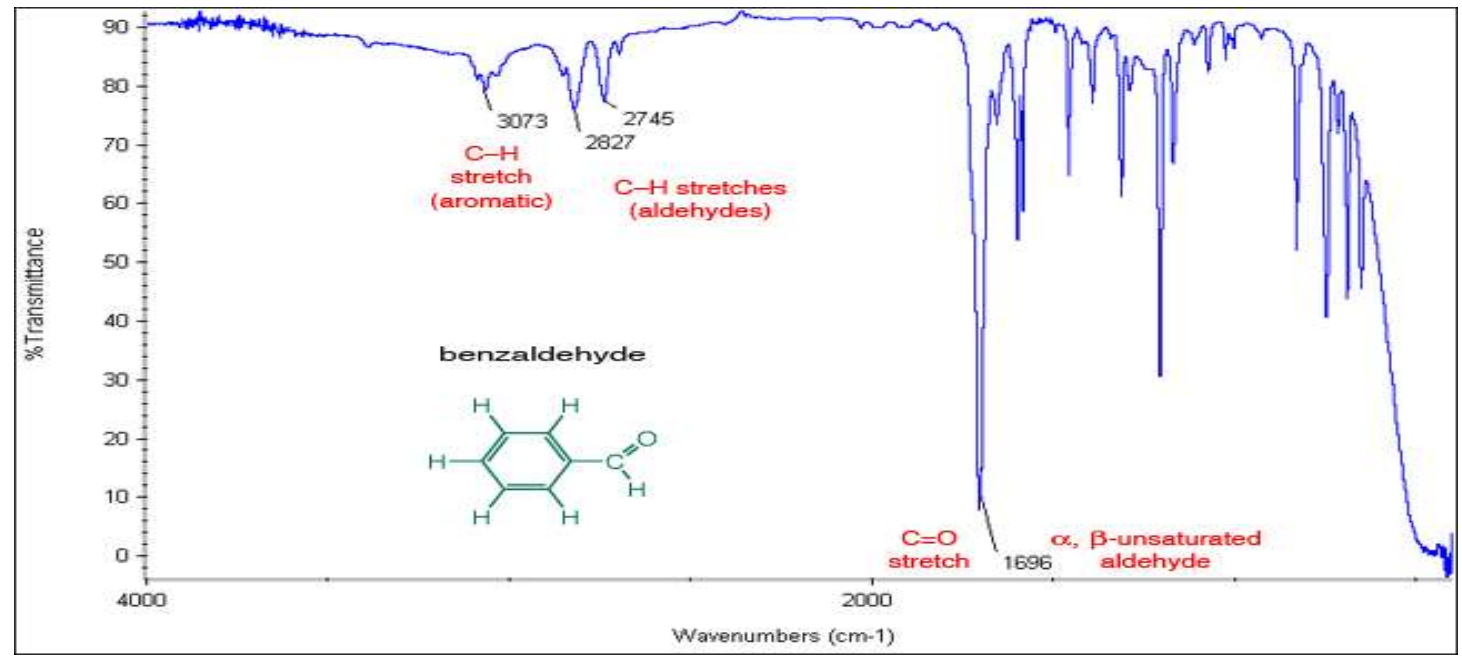

Fig.-6: FT-IR Spectrum of Benzaldehyde

The IR spectral data (Fig.-6) for benzaldehyde shows the presence of the compounds $3073 \mathrm{~cm}^{-1}$ for the aromatic C-H stretching peak. 2827, $2745 \mathrm{~cm}^{-1}$ for aldehyde $\mathrm{C}-\mathrm{H}$ bond and $1696 \mathrm{~cm}^{-1}$ for $\mathrm{C}=\mathrm{O}$ group. All the spectral details reveal that the various reactant complexes undergo an electron transfer reaction in presence of catalysis like Caro's acid and also in the absence of micelles. The spectral data (Figs.- 4, 5 and 6) displaces the presence of reactant complexes before the titration or reaction. The product spectral (Fig.-6) shows the presence of benzaldehyde. So these spectral details confirm that the inner sphere or electron transfer occurred and formed an exact product of benzaldehyde.

\section{CONCLUSION}

An induced electron transfer reaction has been attempted with Caro's acid and Pentaamminecobalt(III) complexes of $\alpha$-hydroxy acids in the presence of NaLS, CTAB, and TRITON-X 100 medium. The reaction exhibits second-order kinetics. In these reactions, the rate of oxidation confirms first-order kinetics each in [cobalt(III)] and [Caro's acid]. The reaction is followed by monitoring the decrease in the absorbance at $504 \mathrm{~nm}$ for $\mathrm{Co}(\mathrm{III})$ complex in a UV-visible spectrophotometer. Product and Stoichiometric analysis were carried out for the oxidation of complexes and free ligands in three different (Anionic, Cationic \& Neutral) micellar Medium. By increasing, micelles concentration and temperature increase in the rate is observed. A mechanism involving the one-electron transfer for the complex and two-electron transfer for the ligand are estimated. The 1.0 mole of cobalt(III) complexes of $\alpha$-hydroxy acids consume 0.5 moles of Caro's acid, whereas 1.0 mole of unbounded $\alpha$-hydroxy acids consume 1.0 mole of Caro's acid. It enunciates the synchronous $\mathrm{C}-\mathrm{C}$ bond fission, decarboxylation and electron transfer to cobalt(III) Centre. An increase in micelles boosts the rate of oxidation of a reaction. Among the three different micelles, CTAB reacts faster than NaLS \& TRITON-X 100. The results obtained with Caro's acid are adequate and show the new reagent as a valuable addition to the existing oxidizing agents. A relevant methodology has been utilized.

\section{REFERENCES}

1. Neha Vyas, Ajay Sharma, Amit Daiya, Anurag Choudhary, Monica Sharma and Vinitha Sharma, European Chemical Bulletin, 2, 859 (2013), DOI:10.17628/ecb.2013.2.859-865

2. Claudio Marcos Ziglio and Keiko Takashima, International Journal of Chemical Kinetics, 27, 1055 (1995), DOI: 10.1002/kin.550271103

3. C.P.Murthy, B.Sethuram and T.Navaneeth Rao, Oxidation Communication, 113, 941(1982), DOI: $10.1002 /$ bscb. 19810900908

4. N.M.I.Alhaji, R.Mamani and K.Kayalvizhi, Chemical Science Transations, 5, 258(2016), DOI: $10.7598 /$ cst2016.1160

5. N.Vijay, D.Mala, C.L.Khandelwal and P.D.Sharma. Indian Journal of Chemistry - Section A, 47, 859(2008). 
RASĀYAN J. Chem.

Vol. 14 | No. 2 |785-793| April - June | 2021

6. R.Abdol, Hajipour, Peyman Hosseini and Arnold E Ruoho, Sulfur and Silicon and the Related Elements 183, 2502(2008), DOI: 10.1021/jo034217y

7. Vinita Kumbhat, Pradeep K Sharma and Kalyan K Banerji, International Journal of Chemical Kinetics, 34, 248(2002), DOI:10.1002/kin.10036

8. Sonu Saraswat, Vinita Sharma and K.K.Banerji, International Journal of Chemical Kinetics, 115, 75(2003), DOI:10.1007/BF02899321

9. A.Thaminum Ansari and K.Subramani, International Journal of Chem Tech Research, 1, 139(2009).

10. D.Preeti Swami, P.Yajurvedi, Mishra and Pradeep K Sharma, International Journal of Chemical Kinetics, 42, 50(2010), DOI:10.1002/kin.20466

11. R.Dayanandan and K.Subramani, Asian Journal of Chemistry, 29, 1948(2017), DOI:10.14233/ ajchem.2013.13142

12. P.N.Naik, S.A.Chimatadar and S.T.Naudibewoor, International Journal of Chemical Kinetics, 42, 336 (2010), DOI: 10.1002/kin.20486

13. Puttawamy and T.M. Anuradha, Indian Journal of Chemistry - Section A, 40, 514(2001).

14. S.Sheik Mansoor and S.Syed Shafi, Arabian Journal of Chemistry, 8, 480(2015). DOI: 10.1016/j.arabjc. 2011.01.031

15. H.Taube, Electron Transfer Reactions of Complex Ions in Solutions, Academic Press, NewYork 1970.

16. Tapas Majumdar and Ambikesh Mahapatra, Indian Journal of Chemistry, 46, 952 (2007).

17. P.Rajkumar and K.Subramani, Research Journal of Chemistry and Environment, 17, 68 (2013).

18. Asheri, Osman, Habibi-Khorassani, Sayyed Mostafa, Shahraki and Mehdi, Progress in Reaction Kinetics and Mechanism, 43, 286 (2018).

19. P.Maruthamuthu and P.Neta, The Journal of Physical Chemistry, 81, 937(1977), DOI: $10.1021 / \mathrm{j} 100525 \mathrm{a} 001$

20. Chetna Gupta, Som K.Mishra and Prem D.Sharma, Transition Metal Chemistry, 19, 65(1994), DOI: 10.1007/BF00166270

21. Surinder Kapoor and Yugul K.Gupta, Journal of the Chemical Society, Dalton Transactions, 4, 473 (1976), DOI:10.1039/DT9760000473

22. S.H.Goh, R.B.Heslop and J.W.Lethbridge, Journal of the Chemical Society (A), 1302 (1966), DOI: $10.1039 / \mathrm{J} 19660001302$

23. Dinesh Panday, Teena kachawa and Seema Kothari, Progress in Reaction Kinetics and Mechanism, 43, 300 (2018), DOI:10.3184/146867818X15319903829236

24. P.Rajkumar, G.Saraswathy, Z.Abdul Vaheith and A.Fiaz Ahamed, Rasayan Journal of Chemistry, 12(3), 1127 (2019), DOI:10.31788/RJC.2019.1235318

25. D.V.Prabhu and Chetana Rana, Rasayan Journal of Chemistry, 11(3), 1084 (2018), DOI: $10.31788 /$ RJC.2018.1131862

[RJC-6225/2020] 